\title{
¿Las tecnologías \\ de información y comunicación \\ son parte de una infraestructura educativa adecuada?
}

Alejandra Torres Landa López

\section{Introducción}

$\mathrm{T}$ odos los días experimentamos cambios significativos en nuestro entorno, por ejemplo, notamos cómo nuestra casa, la oficina, o lugares de entretenimiento se transforman constantemente, y la infraestructura educativa no es la excepción.

Los factores que provocan la evolución de los diversos contextos que he mencionado son múltiples, pero hay dos que podemos subrayar por su importancia y estrecha relación: uno es el evidente crecimiento demográfico de la población, que nos lleva a alcanzar casi los 7,000 millones de habitantes en el planeta, de éstos, 103.3 millones solamente son de nuestro país ${ }^{2}$ y demandan servicios de todo tipo: de salud, trabajo, seguridad, educación, etcétera.

El alto índice de nacimientos en México entre 1940 y 1980, que llegó a 3\% anual, significó que durante el siglo XX la población pasara de 13.6 millones a 97.5 millones; lógicamente, el sistema educativo fue impactado con una alta demanda de lugares a todos los niveles educativos, lo que en consecuencia se tradujo en impulsar fuertemente la construcción de escuelas para el sistema educativo en general. Así, en 1942, la federación crea el Comité Administrador del Programa Federal de Construcción de Escuelas, mejor conocido por sus siglas, CAPFCE, el cual posteriormente se transforma, en 2008, en el Instituto Nacional de la Infraestructura Física Educativa (INIFED). ${ }^{3}$

El otro factor que estamos experimentando es el de los cambios debido al fuerte impulso de las tecnologías de información y comunicación (TIC), las cuales hemos incorporado en casi todas las actividades de nuestra vida cotidiana, creando nuevos paradigmas.

\section{Las TIC en la infraestructura educativa}

En la historia reciente, CAPFCE/INIFED son responsables de construir a lo largo y ancho del país la mayoría de las aulas que hoy vemos en las escuelas y universidades públicas, y es ahí donde surge la primera pregunta: ¿el crecimiento en espacios físicos educativos se ha hecho en México bajo lineamientos psicopedagógicos acordes a los modelos educativos prevalecientes y relacionados con la tecnología educativa vigente en cada momento?

$\mathrm{Al}$ analizar de forma general la literatura disponible, es sorprendente identificar que, la construcción de las aulas en este país, en 1930, trataba de responder a ciertos lineamientos, si se quiere básicos, para propiciar el aprendizaje. ${ }^{4}$ Así, nuestros padres o nuestros abuelos que
Temática relacionada con el trabajo preparatorio realizado en el doctorado en Ciencias de los Ámbitos Antrópicos del Centro de Ciencias del Diseño y de la Construcción de la UAA. Tutor: Dr. Marco Alejandro Sifuentes Solís.

INEGI, "Número de habitantes", 2005, versión electrónica disponible en: http:// cuentame.inegi.gob.mx/ poblacion/habitantes.aspx Miriam Remess Pérez, Fernando N. Winfield Reyes, "Espacios educativos y desarrollo: Alternativas desde la sustentabilidad y la regionalización", en Investigación y Ciencia, UAA, Núm. 42, 2008, p. 49.

Para conocer más del tema, puede consultarse: Lucía Santana Lozada, "Arquitectura Escolar en México", en la revista Bitácora Arquitectónica, Núm. 17, UNAM, México, 2007, pp. 70-75. 
asistieron a una escuela pública contaron con aulas cuyo mobiliario incluía mesabancos acordes a la edad escolar de los alumnos, con salones enmarcados a los costados con ventanas que aseguraban luz y ventilación natural. Incluso, desde 1919, el mismo año de creación de la Bauhaus, se tiene documentada en Aguascalientes la definición de las condiciones que debían satisfacer los edificios escolares. ${ }^{5}$

En su mayor parte, los edificios educativos fueron diseñados para atender necesidades propias de cómo se percibían en la época en que se construyeron; por ejemplo, las aulas, en las que solamente se permitía el acomodo de los escritorios en filas, obligando a los estudiantes a fijar su mirada al frente; los salones contaban con un desnivel, la llamada cátedra, donde el profesor estaba por encima de los estudiantes; los espacios eran propuestos para un enfoque vertical, por señalar que imperaban los rasgos conductistas.

Las aulas respondían básicamente a un modelo escolar centrado en el profesor, quien contaba con un amplio pizarrón en donde escribía de forma interminable ejercicios o colocaba imágenes dibujadas previamente en papel cartoncillo de colores y, si era necesario, disponía además de sus rotafolios. La dinámica de estudio consistía, en lo fundamental, en tomar notas y hacer los ejercicios que el profesor indicaba. El alumno, desde su lugar, tenía que guardar silencio, repetir los contenidos y levantar la mano para hacer alguna pregunta. El proceso se desarrollaba en torno a las directrices que aportaba el señor profesor o la señorita profesora.

Las instituciones educativas respondían a las necesidades de ese momento; posteriormente, se incorporaron tecnologías de vanguardia y, poco a poco, se inició la construcción de aulas isópticas con el fin de proyectar alguna película en $16 \mathrm{~mm}$, lo que requirió bancas fijas, la cátedra del profesor y la posibilidad de oscurecer el lugar. En esos años era frecuente que se adaptaran las aulas, el proyector se colocaba en algún soporte lo más alto posible, mientras que los alumnos y alumnas se sentaban en el piso para dejar libre el paso de la luz. Muchos aún recordamos en nuestra infancia las aulas que habilitaban para proyectar los filmes, el famoso "cinito", donde comúnmente se exhibían temas sobre historia patria o la vida de algún santo o personaje.

Este tipo de espacios mantuvo su vigencia con la aparición del vídeo, ya fuera en versión Beta o VHS, y el esquema de aprendizaje, aunque visualmente más rico, continuó siendo muy semejante al tradicional: un proceso centrado en el profesor, que Paulo Freire ${ }^{6}$ denominó "bancario", y que sólo algunos profesores transformaron al convertir las sesiones fílmicas en objeto de análisis crítico y de reflexión.

Bien o mal, las edificaciones guardaban relación con lo que sucedía en el aula, había una correspondencia lógica entre el edificio, la tecnología existente y el modelo de enseñanza; sin embargo, es evidente que no sigue siendo igual. A fines del siglo pasado todavía había mucha resistencia al cambio, es por ello que el gobierno hace un gran esfuerzo por incorporar las TIC en los ámbitos educativos y que se ve reflejado en el Programa Sectorial de Educación 2007-2012, en donde uno de los principales objetivos es "impulsar el desarrollo y utilización de tecnologías de la información y la comunicación en el sistema educativo para

Boletín Municipal, 24 de agosto de 1919. Educador brasileño e importante influyente teórico de la educación (19211997).

Programa Sectorial de Educación 2007-2012, versión electrónica disponible en: http://www.sep.gob.mx/wb/ sep1/programa_sectorial. 
apoyar el aprendizaje de los estudiantes, ampliar sus competencias para la vida y favorecer su inserción en la sociedad del conocimiento".

Las Instituciones de Educación Superior (IES) hacen un gran esfuerzo al incorporar las TIC en su labor docente, tanto en modelos tradicionales como en la creación de nuevos ambientes de aprendizaje virtuales, ya sea con señal satelital, sistemas de videoconferencias o utilizando alguna Plataforma Educativa en Internet. Ahora es tiempo de hacer una pausa en este camino de cambios y analizar los ambientes de aprendizaje físicos existentes, de tal manera que contemos con espacios físicos adecuados para que, tanto profesores como estudiantes logren los objetivos académicos. Hay que contar con infraestructura educativa en la que las TIC sean parte de ella y no sean una imposición.

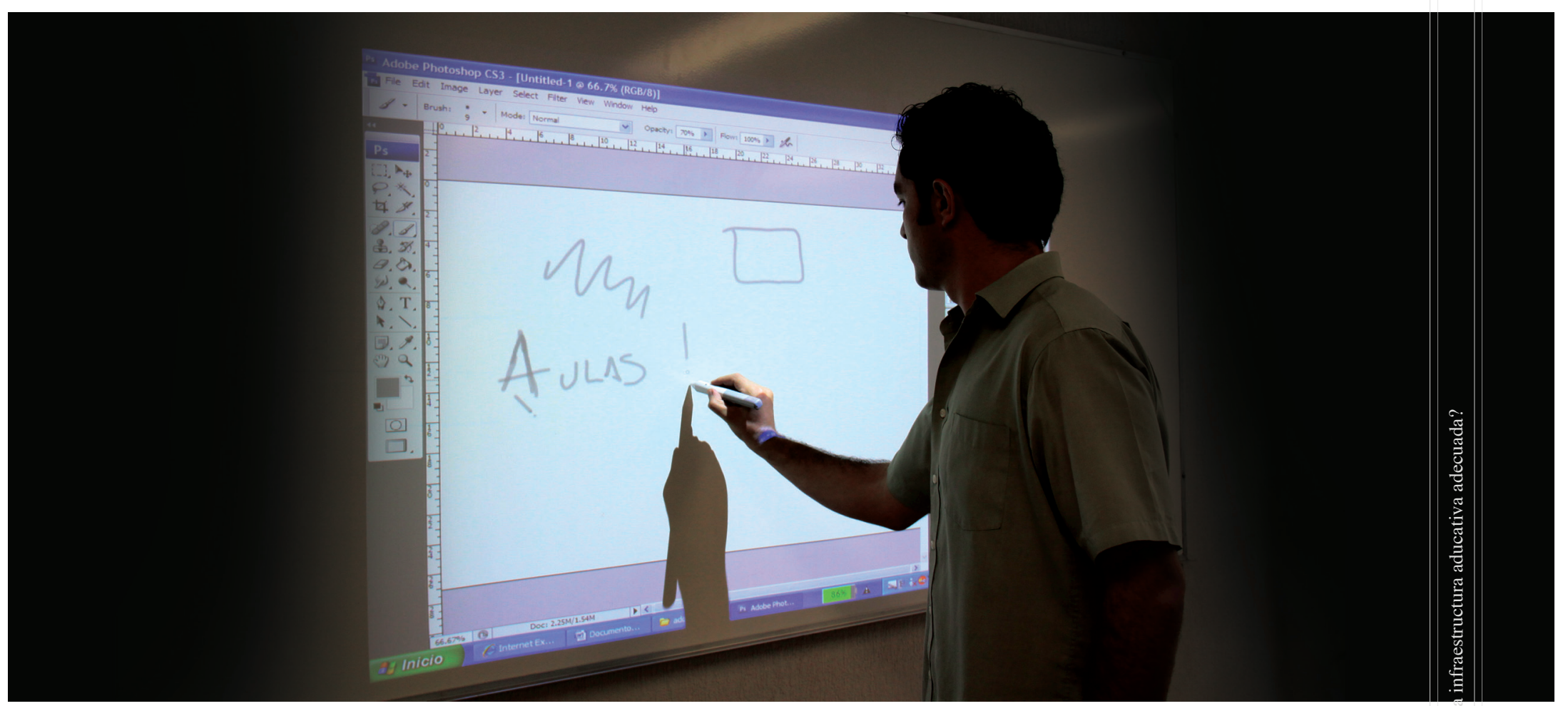

\section{Conclusión}

Las TIC propician nuevas formas de aprendizaje y demandan espacios que responden a estos tres retos fundamentalmente: "el del acceso, el empleo y la integración [...] (AEI). La letra A, corresponde a la necesidad de tener acceso a la tecnología, y la E, del empleo, la disposición y capacitación que tengamos para el correcto uso de las tecnologías de la información y comunicación en los procesos de enseñanza y aprendizaje. Mientras que la letra I alude a la integración de las tecnologías", propiciando una unidad con el espacio físico, ya sea salón, taller o auditorio. Sólo así, la infraestructura educativa permitirá ser el ambiente de aprendizaje físico que logre ser catalizador social y promotor para la construcción de nuevos conocimientos. 